SECTION 30. Philosophy.

Borisova Tatyana Viktorovna candidate of philosophical Sciences, associate Professor of the Department of philosophy and political science, Dnepropetrovsk national metallurgical Academy of Ukraine

\title{
METHODOLOGICAL PROBLEMS OF MODERN PHILOSOPHICAL CULTURE OF THINKING
}

The purpose of our research is the analysis of methodological space philosophical reflection, definition of the role and values in this methodological criticism.

Keywords: thinking, criticism, culture.

\section{МЕТОДОЛОГИЧЕСКИЕ ПРОБЛЕМЫ СОВРЕМЕННОЙ ФИЛОСОФСКОЙ КУЛЬТУРЫ МЫШЛЕНИЯ}

Целью нашего исследования выступает анализ методологического пространства в философской рефлексии, определение роли и значения в нем методологической критики.

Ключевые слова: мышление, критика, культура.

Какой должна быть философская методология? Спешим ответить: метафизически глубокая и конструктивно развивающаяся. Как известно философия разрешает некую долю своих задач в методологической ее части. Развитие философской методологии сегодня осуществляется по пути формирования широкого дисциплинарного пространства методологии в рамках философской культуры мышления.

Контуры предметного поля философии складываются из теоретикоприкладного и культурно-методологического представления о самой философской метафизики. Как не возможна метафизика без онтологии, так на наш взгляд, не мыслима и метафизика без методологической культуры ее осмысления. Считаем, что философское понимание метода, которое охватывает собою процесс познания и самопознания, во многих своих аспектах выходит за границу того, что принято считать научной методологией. И это еще один удобный способ демистификации современного представления об универсальных возможностях и значении самой научной методологии. История рассмотрения этого вопроса своими корнями уходит в эпоху Нового времени, а среди современных исследователей следует отметить В.Лекторского, Р.Карнапа, А.Ахиезера, А.Барабашова, В.Красикова.

Принято полагать, что задачами методологии могут быть и попытки «избавления от лишней метафизичности», которую на нее навевает сама философия. Методология старается «заземлять» некоторые чрезмерно 
абстрактные философские понятия и идеи посредством их взаимокорректировки в массиве гуманитарного знания. При этом философско-методологическая картина реализует себя в качестве прикладной философии, способной помочь «теории и истории философии» сформировать свое дисциплинарное пространство.

Следует очертить круг привлекательных для анализа проблемных моментов в формировании и метафизическом углублении содержания методологической культуры мышления. Задача нашего исследования заключается не в том, чтобы предлагать сразу и исчерпывающий перечень ответов на них, ни даже чтобы уточнять их. Она заключается в осуществлении их философского обоснования и сравнительного анализа на основе конкуренции и актуальности. Ясно, что состояние философской методологии сегодня не катастрофично, но оно всегда сохраняет ценность напоминания и предупреждения от ошибок в познании.

Так к актуальным аспектам современной философской методологии отнесем следующие проблемные моменты:

- выявление специфики культурогенеза методологической рефлексии;

- уточнение философских оснований методологической культуры мышления;

- проблема осознания себя методологией в понятийно-дисциплинарных рамках философии;

- содержательные особенности культурного контекста методологической критики, ее историко-философское измерение;

- попытки обоснования философской методологии в более широком, нежели гносеологический процесс, контексте;

- прояснение смысла таких понятий как «кризис методологии», «целостность методологии», «методологическое наследие», «диалог методологий», «методологический смысл философии», «методологическая дифференциация», «методологический опыт», «конфликт методологий»;

- особенности построения методологической картины мира;

- проблема определения эвристического статуса философской методологии и самой методологической критики;

- роль философской методологии в противостоянии метафизики и диалектики;

- понимание философской методологии как онтологического события в истории философской рефлексии;

- методология как способ борьбы с «романтизмом» стихийной природы человеческой мысли;

- проблема сильных и слабых сторон гуманитарной методологии;

- аксиоматичный характер методов и др.

В целом общий характер поставленных этим перечнем проблемных задач можно попытаться свести к разрешению одного риторического 
вопроса: как возможен «прирост» нового знания в методологическом пространстве философии?

Возвращаясь к проблеме аксиоматичного характера методов, задаемся сомнениями: миф это или реальность? Как с этим бороться и стоит ли это делать? Однозначно дать ответ на эти вопросы нам не представляется возможным, поскольку его просто не существует в природе. Для одних методов присущая аксиоматичность - это принципиальная их основа и избавиться от нее - означало бы лишиться самого метода. Особенно ярко это видно на примере диалектического метода, для которого противоречие объявлено нормой. Это может, в свою очередь, послужить основанием для скептически настроенных умов, объявить диалектику худшим видом догматизма. С чем мы все же не согласны.

Важно отметить, что современное состояние размежевания философского знания на множество дисциплин создает дополнительные трудности в понимании самой социальной реальности. Вопрос о методологической транскрипции этого знания становиться проблемой для мыслителя. Многовекторность и распорошенность материала ставит перед самой философской методологией задачи поиска универсальности и метафизической гибкости для его обработки. Следует признать, что в XX веке философская мысль отчасти решила этот вопрос для себя уклонением в сторону - уходом в построение относительных методологий. Ясно, что сфера их применения уже сужена и носит «региональный» характер с целью дальнейшего ее применения уже не в качестве глубинных оснований метафизики, а для какой-то характерной онтологической области философского знания. Такое положение дел содержит как положительные, так и отрицательные стороны, но в любом случае составляет собой часть всей методологической культуры мышления. Все это так же может свидетельствовать о живом желании со стороны методологической критики самоопределиться в философской рефлексии.

В вопросе о «конфликте методологий» нами видятся некоторые смещения акцентов на вопрос о «конфликте методов». Возможно ли, что конфликт методологий - это излишнее обобщение, в то время как, сам конфликт заключается между методами в рамках одной единой методологической дисциплины? Яркой иллюстрацией к этому может послужить противопоставление метафизики и диалектики как равноправных методов в рамках самой целостной философской методологии. Если на уровне метода разворачивается противостояние диалектики и метафизики, то в этом случае видится ограниченный эвристический потенциал диалектики, тут она уже не может претендовать на объяснение социального мира, как это было в мире природных и физических явлений. Но вместе с тем, она способна быть полезной как отличное дидактичное средство в воспитании гибкого философского мышления, накопления ним опыта и демонстрации его предельных 
возможностей. Оппозиция между метафизикой и диалектикой в таком случае в контексте целостности самой философской методологии теряет свою силу, и становиться ненужной, если не сказать больше - даже вредящей.

Понятие методологии трудно сделать философски точным и функционально емким, но оно интуитивно-принудительно наталкивает субъекта познания на идею о возможности и способах организации мышления, его некоторой упорядоченности.

Степень самоотчетности философской методологии в ходе ее культурно-исторического и научно-философского развития возрастает и это следует понимать как позитивный симптом для развития всей философской мысли. Применяемые исследователями методы, равно как и формы организации изложения материала должны постоянно подвергаться проверке и осмыслению. Как показывает опыт, методы и методологические установки обладают колоссальной устойчивостью, преемственностью и способностью к воспроизведению в рамках различных эпох с их философскими картинами мира.

В связи с этим возникает вопрос: ведет ли смена философской картины мира к смене методологической картины мира? Думается нам, что ответ на него может быть сведен очередной раз к проблеме критического философского анализа, его целесообразности и культурно-исторической ценности. На это обстоятельство обращает свое внимание и современный российский мыслитель А.Ахиезер в работе «Философские основы социокультурной теории и методологии»: «Возникновение нового смысла возможно через критику. То есть через отказ от преклонения перед сложившейся культурой, накопленными смыслами, через отказ о сакрализации культуры и при повышенном внимании к ограниченности любой экстраполяции и интерпретации. Необходим отказ от представлений, что осмысление возможно без всякого опосредования ранее сложившимися смыслами. Критика есть уверенность в том, что постоянное изменение, усложнение мира требует ответа посредством углубления культуры, формирования смыслов, стимулирующих подъем способности противостоять новым опасностям. Критика есть способность рассматривать изменение смыслов, культуры как ценности. Критика есть по сути оборотная сторона формирования новых смыслов, постоянное стремление в сфере МЕЖДУ создавать необходимые предпосылки для этого процесса» $[1 ; 32]$.

В силу этого обстоятельства основной пласт теоретикометодологического знания философии существует сегодня в виде некого симбиоза научного и философского знания, провести между которыми пограничную линию архисложно. Идея метода может претерпевать от этого философско-методологического атомизма. При всех своих достоинствах и познавательных возможностей сама философская 
методология не может служить для исследователей механизмом по производству философски обоснованных результатов. Иными словами, она, безусловно, учувствует в «изготовлении продукта», но самим продуктом быть не может. Почему? Потому как вне онтологии и всей метафизики она не мыслима. За ней крепко держится статус одной из структур всего философского знания. «Автономное», изолированное истолкование философской методологии и сущности ее усилий может послужить основанием для негативной оценки философии, представлении о ней как о второстепенной. Дело в том, что наличие философскометодологических результатов предполагает последовательное культурноисторическое развитие той области знаний, в которой такие результаты появляются (т.е. антропологии, гносеологии, аксиологии, этике и т.д.). Это значит, что созданная мыслителями одной эпохи методологическая картина мира со временем будет обновлена последующей в большей или меньшей степени.

В новой картине мира отражаются или изменяются прежние формулировки, трансформируется их философско-онтологическое и гносеологическое обоснование, устанавливается новая конфигурация связи прошлого и нового знания, методов, подходов, а так же критическая оценка их значимости и актуальности. Потому не стоит изучать природу человека исключительно по текстам Платона и Р.Декарта. Их учения обретают свою современную философско-методологическую интерпретацию. Сделанное ими в рамках философской антропологии не устаревает и составляет предмет истории философской мысли. Философские концепции и их методологическое обоснование, безусловно включены в круговорот культуры не только после смерти их создателей, но и после очередной в истории философии их переоценки. Оттого предметное поле философии и сфера методологического дискурса шириться от эпохи к эпохе. Природа философского знания такова, что методологические труды прошлого и сегодня дают оригинальные ответы на многие вопросы метафизики. Однако, верно и то, что эти ответы не всегда удовлетворяют окончательно всех, а только лишь их авторов.

Важно обратить внимание и на тот факт, что идея методологического плюрализма может заявить о себе не только как проблема философской методологии, но и всей структуры гуманитарного знания. Было бы иллюзией полагать, будто разрешение свободно мыслить само по себе и так же произвольно использовать в исследовании методы - служит гарантией развития науки, позитивного расширения границ ее предметного поля. За исследователем всегда сохраняется право выбора методологических композиций, а так же свобода их конструирования, сопоставления и противопоставления друг другу, но все это должно осуществляться в рамках одной системы координат. В качестве последней может выступить картина мира или тип мировоззрения. Так называемое 
«грехопадение» субъекта познания случается тогда, когда производится тотальное смешивание ним разнородного методологического и метафизического материала, некорректное использование методов. Например, метод перенесения законов развития природы на мир социальных или трансцендентных явлений, не учитывающий специфики последних. Он был уязвим с самого начала его применения. Это породило в философии много парадоксов и противоречий, начиная с философсковульгарного использования научного категориального аппарата в сфере экзистенциальной философской мысли. За категориями закреплено право «кочевать» из одной картины мира в иную (например, из естественнонаучной в философскую). Задача мыслителя философски обосновать смысловой статус категории на «новом» для нее месте.

Не следует думать, что если такая проблема стара для философии, то ей уже найдено верное решение. Каждая эпоха, равно как и каждое философское направление решает ее в свой способ. В этом случае важнее не столько найти ей окончательное разрешение, сколько не сбрасывать со счетов и понимать как проблемный момент в исследовании. Это упреждает дальнейшее развитие философской культуры мышления от многих ошибок не только в методологической ее части.

По сути дела, как нам видится этот вопрос, проблемы по этому поводу начинаются с момента принятия за основу идеи об относительности понимания философских (этических, эстетических, психологических, правовых, социологических, педагогических и др.) категорий. Сегодня «эпидемия» относительного заостряет многие вопросы в философской онтологии и антропологии. Поскольку, происходит нивелирование понятий высокого, истинного, правильного, хорошего. Теряется, распадается целостность в понимании картины мира и человека, к которой призвано все в бытии. Если уже нет понимания «хорошего», то есть понимание «разного». К примеру, понятие «свобода» или «красота», в христианском их понимании, онтологически неразрывно связаны с бытием Бога. Они уже не могут «зависать» в статусе онтологической относительности. Потому и нужна продуманная ответственная со стороны субъекта познания методологическая артикуляция понятийнокатегориального аппарата философской рефлексии. И никакие высоколобые философские или научные концепции не имеют право теснить в этом методологию. Мы не усматриваем в этом скрытого превосходства методологического знания над всем иным, скорее это ее прямая и первоочередная задача.

Особая роль методологии в системе философского знания служит основанием для большего распыления мнений относительно нее самой. Считается, что даже философы одной школы или одного направления могут использовать схожий набор понятий и придавать им одинаковый смысл. Однако, сходство используемых понятий и методов при ближнем 
их рассмотрении фиксирует все же различие. В этом случае философская методология выступает неким «Прокрустовым ложем», в хорошем смысле этого сравнения. Единство духовных исканий мыслителей в методологическом их преломлении раскрывается широким спектром различных философских концепций. Выходит, что методология - это путь и способ развертывания мысли.

Нас интересует свобода и познавательный масштаб философской методологии именно как ее осознание себя частью всей философской культуры мышления. Это еще не означает, что сама философия замыкает методологию в поле своих образов, но она довлеет над смыслом используемых понятий и методов. В этом случае целое определяет части, а не наоборот, сохраняя целостность философско-методологического знания.

Высокий уровень философской мысли может быть нам продемонстрирован так же, когда философская проблема мыслиться не только как образ, но и методично, посредством используемых методов анализа. Скептики могут заподозрить в этом моменте «удаление» от сущности самого проблемного вопроса. Но эта дистанция - дистанция возможного его решения, иными словами, смена ракурса взгляда на проблему приближает исследователя к еe решению посредством методологии, но не в ее рамках.

Содержание и логика изложенного нами материала позволяет прийти к следующим умозаключениям.

1. Методологическая картина мира представляет собой систему методов и принципов, что позволяют через понятийно-категориальный аппарат философской методологии раскрыть онтогносеологические, антропологические, аксиологические основы философской эпохи или отдельной философской концепции.

2. Саморазвитие и самообновление философской методологии должно протекать в рамках всей структуры философии с корректным заимствованием понятий, категорий и методов из других областей гуманитарного и естественнонаучного знания.

3. Методологическая транскрипция философских вопросов призвана отражать смысловую целостность, единство и преемственность историко-философского исследования. Единство философии обеспечивается не только единством жизненных проблем, но и нормативным характером самой философской методологии.

4. Философско-методологическая критика по своей сути представляет собой путь развертывания эпистемологического процесса с элементами эвристики.

\section{Литература.}

1. Ахиезер А.С. Философские основы социокультурной теории и методологии // Вопросы философии № 9 - М. - 2000. - С. 39 - 45. 